stimuli away from the subjects, and the question which the subject has to answer should be reduced to the simplest possible terms. Where the subject is asked to make a comparison, the experiment should begin with cases in which the difference between stimuli is large and the subject has no difficulty in answering the question. An interesting and so far unexplained result was obtained in the experiments described; it proved to be of some importance whether the reference tone or the test tone was varied when presenting the stimuli, as a change in this respect introduced a consistent change of about 4-5 phons in the results.

The chairman (Mr. H. L. Kirke) stressed the need for keeping random variations in equipment small in comparison with the quantities to be measured. $\mathrm{He}$ also mentioned that the 'multiple criterion' technique has been successfully used by the B.B.C. in measuring the unpleasantness of interference in radio reception. In this particular experiment, six criteria were employed. The discussion, he said, had indicated a real need for some consideration of the terminology to be used in connexion with subjective work.

An account of experiments on the adaptation of the ear to sound stimuli was given by Dr. J. D. Hood (Otological Research Unit, Medical Research Council), who suggested that adaptation might have an important bearing on many subjective acoustic measurements. His experiments have demonstrated a difference between the results obtained by alternate and simultaneous loudness balances.

Mr. D. L. Richards (Post Office Research Station) dealt with the application of probit analysis to the calculation of confidence limits with respect to the results of subjective measurements. The experiments discussed were designed to determine the loudnesslevel necessary to provide a usable telephone system. When the proportion of subjects who judged the system to be usable was plotted against the loudness level, the results gave a probability integral. The standard deviation of the corresponding normal distribution gives the measure of reliability of the judgments. The experiments also showed that the judgments of one subject are very reliable in the course of a single experiment, but that the absolute levels for that subject vary on different occasions.

A comprehensive account of the part played by subjective measurements in clinical work on deafness was given by Dr. T. S. Littler (Wernher Research Unit, Medical Research Council). He pointed out the difference between measurements in which the subject has to interpret what he hears, and those in which he has simply to register that he hears something. In the deafness clinic, both types of measurement are made in the forms of pure tone audiometry and speech audiometry. Certain limitations are imposed by the conditions in which such tests are carried out. The time available is short and so the tests must require little conditioning of the subject. With deaf patients, it is particularly necessary that all instructions should be precise and simple; in articulation tests employed in speech audiometry, only meaningful words can be used, and the material has to be suitable for the particular patient. Care is necessary to avoid unwanted subjective effects, such as the setting up of transients in the ear through the sudden onset of a pure tone signal, or excessive practice effects in speech audiometry. Assessing the true performance of hearing aids is an operation which must be based on subjective measurements ; and, where objective methods are used for the purpose, their results should be correlated with subjective judgments.

Mr. J. G. Holmes (chairman of the Colour Group of the Physical Society), in commenting on the need for an agreed terminology, gave a résumé of the work done by the Colour Group in drawing up a suitable terminology for use in its own field.

Mr. R. L. Dadson (National Physical Laboratory) discussed the technique of loudness-balance experiments particularly, and said that the order in which different stimuli are presented to the subject should be random. Experiments at the National Physical Laboratory in which the subject was allowed control of the stimulus gave results which agreed well with those of measurements in which he had no control, although the scatter of the latter was rather greater.

D. B. FRY

\section{GROWTH AND FORM}

$\mathrm{O}^{\mathrm{s}}$ March 16 the Royal Society held an all-day discussion meeting on the "Measurement of Growth and Form". Prof. S. Zuckerman introduced the ten formal contributors by saying that this was the fourth symposium having growth as its subjectmatter that had been held during the past five years. The first ${ }^{1}$ had taken the form of a Festschrift for Sir D'Arcy Wentworth Thompson, whose lasting influence on current thought would be apparent throughout the proceedings ; the second, a conference at Princeton in 1946, the proceedings of which had just been published ${ }^{2}$; the third, the Summer Conference of the Society for Experimental Biology in $1947^{3}$. The present conference was to be deliberately narrower in scope than these last two, since it was less concerned with growth mechanisms than with the measurement of growth and form. This restriction might make it possible to reach agreement on a variety of technical problems. What, for example, was the status of growth equations: were they empirical or could they be arrived at deductively? What was the relationship between the curve of growth of a single organism and that compiled from the means of massed statistics ? Was the allometry equation a valid formulation of differential growth, and what was its relationship to D'Arcy Thompson's method of transformations ? Prof. Zuckerman called for a clear statement of the differences between the modes of growth of plants and animals, and asked how far methods appropriate to the description of animal growth were applicable to the growth of plants.

Prof. F. G. Gregory took up the last question. Plant growth, he said, is in a sense permanently embryonic, in that change of form endures throughout the plant's life-history. In the main, the form of the higher plant is governed by the relative development of leaf and stem; the tendency for secondary axes or branches to be produced; the absolute sizes and shapes of leaves and their arrangement in the stem; and the duration of growth of primary and secondary stems. The form of the leaf was the subject of mathematical description by D'Arcy Thompson; but such a description did not illuminate the actual mechanism of growth, for the shape of the leaf is independent of cell size or shape and is a function of local variations in the rates of cell division, apparently related to the distribution and synthesis of auxins. The comparison of the growth processes of different organisms promises to be more rewarding. A study 
of the modes of increase of height and weight, leaf surface, the number and dimensions of nodes on the stem, and the number of branches, flower buds and fruits makes it possible to appraise the influence of climatic and nutritional factors in governing growth and yield. Prof. Gregory pointed out that such analyses have yet to be extended to growth in controlled environments, for the study of which there are at present no facilities in Great Britain. Even so, the study of mature organs will not suffice, for the problem of plant growth and form centres on the meristem or growing points.

Dr. G. M. Morant gave a lucid analysis of one particular problem of human growth : to determine from the existing records (which relate to more than two million individuals) the secular change in the height of British males over the past hundred years. $\mathrm{He}$ said that the two most relevant statistics that emerge from an analysis of the records are the maximum mean height and the age of its achievement. The age at which the maximum mean height is achieved makes a clear distinction between social classes, being earlier in the more favoured; and within any one such class, the fitter (for example, those selected for the armed forces) mature earlier. In the male population of Britain as a whole, the age for normal attainment of maximum height has fallen from 26 years in 1880 to $21 \frac{1}{2}$ years in 1945 ; the fall has latterly become more rapid, and is more striking in the socially less favoured. The maximum mean height itself, $67 \frac{1}{2}$ inches for the general population according to the best estimate, appears to have remained stationary. But, he asked, why do the height-age distribution tables reveal a decline in height after its maximum between eighteen and thirty years? One possibility is a selective deathrate, taller men being supposed to be the more vulnerable. A second is that there has been a secular increase of height in the population; from which it would follow that the older men, those earlier born, would be the shorter. Dr. Morant finds neither view acceptable, the decline is probably due to a real decrease in the height of individuals, perhaps because of the shrinkage of intervertebral disks or to a change in the muscles and joints affecting the maintenance of the erect posture. At all events, British adolescents are taller now than formerly. The maximum mean height is stable, but its rate of attainment is not, and the secular change of the growth-curve has been due to a speeding-up of the rate of growth. This interpretation supports the view that the height attained at maturity is genetically determined, though its rate of attainment is within wide limits governed by differences in the conditions of life.

Dr. J. Hammond's contribution dealt with the measurement of the growth and form of farm animals. Of the several methods of representation that might be chosen, the growth-rate curve, expressing the weights gained per unit of time, has proved to be the most useful both for the total live-weight and for the weights of the constituent tissues. Since the constituent parts grow at different rates, the form of the animal and the proportions of bone, fat, muscle, etc., vary throughout the period of growth. These proportions can be deliberately controlled within wide limits by retarding or advancing the growth-rate nutritionally at different epochs of life, taking advantage at the same time of the fact that the different tissues respond very unequally to the deprivation of food. Pigs fed on a high plane of nutrition when young, that is, when bone and muscle are growing quickly, develop a large frame, and fail to grow fat when dropped to a low plane of feeding later in life. Pigs fed on a low plane when young have stunted frames, and when later raised to a high plane deposit large quantities of fat on a shortened body. The facts discussed by Dr. Hammond have led to the formulation of a theory of the partition of nutrients to the different tissues of the body according to the order of their development in the individual or to their metabolic activity.

Prof. S. Westoll spoke of the relatively new but now rapidly expanding subject of growth-studies on fossil material. Progressive changes of proportions in the evolutionary history of a group are better understood, he said, in terms of a transformation of growth processes than by the mere comparison of adult stages ; but material for such a study is understendably hard to come by. As a rule, it is, of course, obligatory to use size rather than age as the independent variable in studies of fossil growth, although it is true that some fossils (notably corals) have given evidence of seasonal growth. In general, it is hoped that an analysis of secular changes in the modes of growth will make it possible to appraise the significance of 'orthogenetic' trends in evolution, as has already been to some extent possible for the classical case of self-occlusive shell-coiling in Gryphoea. Prof. Westoll spoke critically of the palæontologists' reluctance to discard the Law of Recapitulation, and referred to the high interpretative value of the concepts of pædomorphosis and neoteny.

Prof. Westoll mentioned an interesting outcome of size-frequency analysis in fossils: the possible existence of sexual dimorphism in the small Permian brachiopod Dielasma elongata.

The appropriate methods for describing differential growth were discussed at some length. Dr. J. S. Huxley began by reviewing the history of the use of that equation for differential growth which, in its simplest form, asserts that the size of an organ grows in proportion to some constant power of the size of the whole. The equation had been used by Dubois and Lapique and others, particularly to represent brainweight as a function of body-weight; but Huxley was the first to investigate its general applicability. The allometry method not only reveals an order and coherence in the changing ratios of the sizes of the parts of the body, but also shows up, in the form of growth gradients, the distribution through the body of what Prof. Zuckerman had called patterns of formchange. The existence of such graded changes of shape is, of course, implicit in D'Arcy Thompson's geometrical treatment of transformations, but the merit of the allometry method is that it makes the information explicit. Dr. D. Sholl was inclined to think that the allometry formula is scarcely acceptable when dealing with simply proportionate growth, that is, mere magnification, though it is true that simple magnification can be represented as a special case of allometry, namely, that in which the value of the exponent is unity. Prof. P. B. Medawar urged that Huxley's mode of formulation is acceptable even if the exponent of the allometry equation varies as: a function of age : whatever merit can be attached to the use of the specific growth function

$$
\frac{1}{W} \cdot \frac{d W}{a t}
$$

for describing change of size, should justify the use of a ratio of such functions for describing the differ- 
ential growth of two parts, for the exponent of Huxley's equation is simply a ratio of two specific growth-rates. Just as the use of the specific growth function is by no means confined to systems growing at a constant specific rate, so Huxley's mode of formulation may still be appropriate even when the ratio of two specific growth-rates is found to vary. The theoretical background of Huxley's equation is simply the theorem that biological growth is fundamentally multiplicative in type-a generalization not invalidated by the existence of systems showing accretionary growth, because the growth of accretionary products like nails and hair is, in fact, subsidized by a multiplicative growth system, that of the epidermis. Pr of. Medawar ended by sketching the theoretical background of the method of transformations, treated analytically and "put into continuous motion". He said that it is not "superior" to Huxley's method, but some special types of information can be extracted more easily from it. Dr. Sholl believed that the 'vector' method of growth analysis first applied by Richards and Kavanagh" has not been developed as fully as its promise justified; this is a pity, because the analytical methods appropriate to it are very well understood.

Prof. J. B. S. Haldane said that the representation of allometric growth by the regression of one variate on another is perhaps justifiable if body-weight be the independent and the size of a small organ the dependent variate, but is certainly unjustifiable when the length and breadth of the same organism or organ are compared. What line or curve best represents the relationship between two such variates? Kermack and Haldanes have pointed out that the line $(x-\bar{x}) / \sigma x=(y-\bar{y}) / \sigma y$ is invariant under change of scale and impartial between $x$ and $y$. If this line does not pass through the origin, an allometric relationship between $x$ and $y$ may be suspected, and if $X=\log x, Y=\log y$, then $(X-\bar{X}) / \sigma X=(Y-\bar{Y}) / \sigma Y$ may be taken as the axis of allometry ${ }^{8}$. If $X$ and $Y$ are normally correlated, the coefficient of allometry can be represented by

$$
\alpha=\frac{\sigma Y}{\sigma X}=\sqrt{\frac{\overline{\log \left(1+V_{y}^{2}\right)}}{\log \left(1+V_{x}^{2}\right)}}=\frac{V_{y}}{V_{x}} \text { nearly, }
$$

where $V_{x}$ and $V_{y}$ are the coefficients of variation of $x$ and $y$. The corrections for non-normal correlation have proved to be small.

In later discussion, Dr. E. C. Reeve referred to the genetical aspects of relative-size allometry revealed by studies on the inheritance of body-size in Droso. phila. The variations in wing-and thorax-length in a given stock must be analysed in terms of the genetic and environmental correlations between the two dimensions. The change in one dimension when the other is selected for large size can be said to lead to a new concept, that of genetic allometry.

Several speakers referred to statistical and other difficulties in the derivation and use of growth equations. Prof. Medawar singled out two. A curve of growth in time compiled from the mean weights of a population of organisms is in reality a curve demonstrating the mean contribution of an individual to the biomass of the population. It might, and often does, differ profoundly from the growth curve of the individual. Dr. Sholl and Dr. F. Yates re-emphasized the danger of error arising from this source, and Dr. Sholl pointed out that Richards and Kavanagh ${ }^{4}$ have worked out acceptable solutions for many of these difficulties as they arise in the study of allometry. Dr. Sholl particularly stressed the need for applying statistically efficient tests for the goodness of fit of growth equations : it is not good enough to fit 'by eye'. A second hazard of a rather different sort was pointed out by Prof. Medawar, and it provoked some discussion later on. If Huxley's allometry formula is a theoretically valid description of the differential growth of two parts of an organism of dimensions $y$ and $z$, then it cannot at the same time be a theoretically valid description of the differential growth of the quantity $(y+z)$; for, as J. B. S. Haldane pointed out many years ago, the sums and averages of these simple parabolic functions are not themselves functions of the same sort. Dr. Yates was critical of statistical evidence revealing the presence of growth gradients : the trunk region of the human being cannot, for example, be said to show within itself the growth gradient that a transformation analysis had suggested, although the head shows a progressive relative decrease in size and the lower limb a progressive relative increase.

In his introductory address, Prof. Zuckerman had asked for a decision on the status of growth equations : were they empirical or could they be deduced from prior assumptions relating to the partition of nutrients, the balance between anabolism and catabolism, the 'gearing' of growth by metabolic master reactions, and so forth ? The general feeling of the meeting was that growth equations are primarily empirical descriptions of growth. Dr. Sholl pointed out that there are 296 different sorts of growth formulæ and that some deduced formulæe contain so many para. meters that they are highly adaptable to a great variety of empirical data. An equation can be fitted to any finite set of points if it contains a sufficient number of parameters. At the same time he felt that it is not good enough to say that growth equations are purely empirical, otherwise it would always be sufficient to fit any $n$ points with a polynomial of order $(n-1)$. Prof. Haldane said that individual growth curves could be averaged in two.ways: the mean stature (or other dimenaion) might be plotted against age; or the stature, or fraction of the adult stature, might be plotted against the age at which it is achieved. But neither method gives a representative growth curve. One should try to fit a small number of parameters to each curve-four to six should be enough-one of which would represent approximately the age of puberty and another the total extra growth associated with puberty. A representative growth curve could then be obtained by using the mean or, better, the median values of these parameters ; and if some prove to be correlated, the number of independent parameters will be correspondingly reduced. The parameters of such curves would have much more biological significance than those of curves representing averages.

Not all contributors were satisfied that mathematical analysis of changes of size and shape is a fruitful procedure. Prof. C. H. Waddington urged that what is required is the resolution of a growth process into its contributory causes, as the morphogenesis of the wing of Drosophila is the outcome of (among other things) changes of cell-size, cell-shape and cell-number, and the pattern of the distribution of such changes in the developing wing. Such an analysis, he felt, should precede, not follow, the formal analysis of size and shape. Prof. J. Z. Young pointed out that, although formal description is necessary and desirable, it is not an end in itself, and might be 
mischievous if growth were analysed in too remote isolation from the complex of activities that endow the organism with the properties of a self-maintaining system. Nor is it by any means true that all differences of organisation can be quantitatively treated : for example, the differences between the organisation of the skins of Amphioxus, lamprey and man are insusceptible of formal numerical treatment and are more important than differences that can be so treated. They are intelligible if one thinks of the skins as parts of biological systems adopting different modes of self-maintenance. One organisation can be said to be 'higher' than another in a sense which takes into account the efficiency of self-maintaining systems in relation to the range of variation of the environment in which the faculty of self-maintenance is exercised-roughly speaking, in relation to the 'difficulty' of self-maintenance. 1 "Essays" on Growth and Form Presented to D'Arcy Wentworth
Thompson." Ed. by W. E. le Gros Clark and P. B. Medawar (Oxford, 1945).

2 "The Chemistry and Physiology of Growth." Ed. by A. K. Parpart (Princeton, 1949).

"Growth in Relation to Differentiation and Morphogenesis." Symposia Soc. Exp. Biol., No. 2 (Cambridge, 1948).

" Richards, O. W., and Kavanagh, A. J. (1945). In "Essays on and Form", op. cit.

'Kermack, K. A., and Haldane, J. B. S. (unpublished).

- Cf. Teissier, G., Biometrics, 4, 14 (1948).

\section{THE NEW JOHN INNES HORTICULTURAL INSTITUTION}

$\mathrm{T}$

HE opening of the new John Innes Institution was celebrated at Bayfordbury on June 2 before a gathering of about five hundred visitors, including representatives of some fifteen countries. The visitors were welcomed by the chairman of the Council, Colonel F. C. Stern, who gave an appreciation of the Institution's work and an acknowledgment of the contribution of all who had helped with the removal from Merton. A formal address of opening was given by Lord Cranborne, who referred to the widening importance of the genetics research of the Institution in agriculture, medicine and human affairs generally. Lord Cranborne presented the Institution with a key to Bayfordbury Park, given by the then owner, William Baker, to the first Marquess of Salisbury-as a token of the goodwill which then and now existed between neighbours.

The director, Dr. C. D. Darlington, referred to the purpose of the Foundation, and the scope of the work that would now be undertaken. A vote of thanks to Lord Cranborne was then moved by Lord Rothschild, chairman of the Agricultural Research Council. The visitors were able to see exhibits of the work in the laboratories, the library, the glasshouses and the experimental fields. The National Rose Collection and the Pinetum were also shown.

The mansion of Bayfordbury and the surrounding estate of some four hundred acres were bought by the John Innes Trustees in May 1945 (see Nature, 156, $586 ; 1945$ ). It was intended to serve as a home for the Horticultural Institution, which was established at Merton in 1910. It is sixteen miles due north of London, one mile from the county town of Hertford and ten miles from the sister research station of Rothamsted. The house was built in 1760, and the gardens were laid out at the same time. Great extensions were made later. In 1810 the "Bury", as it came to be called, was enlarged, and by 1840 stable buildings, a walled garden, an artificial lake and $\mathbf{a}$ pinetum for the acclimatization of exotic species had been laid out by the owners, the Baker family.

On these foundations the John Innes Institution has set up its own organisation. The mansion has undergone little change except repair and the lighting and heating works. Of its rooms, sixty will be used for work and twenty for residence. Laboratories, library and offices have now spread out to fill twice their former crowded space. The gardens have been restocked largely with gifts from private gardeners and other institutions. The stables have been converted into garden offices and flats. The level of the lake has been raised for use as a reservoir. A village, to be known as Broad Green, has been built for the staff, of whom twenty families have been accommodated on the estate. New water and electricity supply and drainage systems have been installed for the three units and also for the fourth and largest which is comprised by the glasshouses.

The design of the glasshouse unit, which covers a couple of acres (half an acre under glass), has been the subject of special study carried out under the auspices of a committee of the Ministry of Agriculture. The purpose was to use the whole arrangement as a many-sided experiment-primarily in orientation (east-west against north-south) and secondarily in materials (wood against steel and duralumin) and in systems of ventilation and heating. In addition, new methods of artificial lighting, temperature and humidity control have been used, and a mechanized system of composting and soil sterilization has been installed. It was very much regretted that the curator, Mr. W. J. C. Lawrence, who has been responsible for these enterprising developments, was prevented by illness from attending the celebration.

In parallel with the glasshouse construction, new controlled-condition rooms have been built in the mansion to meet the requirements of Dr. D. Lewis and others in which the temperature can be varied from $-8^{\circ}$ to $+40^{\circ} \mathrm{C}$., and at the same time a wide range of lighting and humidity can be maintained. These new methods of physiological control are demanded by the recent growth both of genetical and cytological research where studies of heredity and development find a meeting-place.

Of the land, about a half has now been taken in hand. A hundred acres have been used for fruit and experimental plantations; and another hundred are being used as a source of timber, stakes and gravel. M. M. B. Crane's orchards of new seedlings are now well established. The important specimen trees of the park are being tended and restored, named and labelled, and a great number of dead trees have been cleared. Some 120 species and hybrids (nearly all with their chromosome numbers attached) have so far been planted out as a beginning of the National Rose Species Collection.

The removal of the John Innes Institution has been an experiment in transplanting not merely work and trees and equipment but also people from urban to rural surroundings. It is proper that research on the cultivation of crops and gardens should be carried out in the country, where the results of the research have to be applied and with a freedom of space which only the country can provide. If the trained men are available in the future to take advantage of these splendid new. opportunities, agricultural and horticultural research should greatly benefit by the opening of Bayfordbury. 